\title{
Whence the Critical Zone?
}

\author{
SUZANNE P ANDERSON ${ }^{1}$ AND SUSAN L BRANTLEY ${ }^{2}$ \\ ${ }^{1}$ University of Colorado Boulder \\ ${ }^{2}$ Pennsylvania State University \\ Presenting Author: Suzanne.Anderson@colorado.edu
}

Critical zone science has emerged as an engaging approach to surface processes over the last twenty years. The codification of ideas under the deliciously ambiguous and moldable term "critical zone" began when sedimentologist Gail Ashley injected it, and the concept of integrative study of Earth's surface, into the influential 2001 U.S. National Research Council BROES report. That report placed $\mathrm{CZ}$ science at the cutting edge of the geoscience agenda. The idea of interacting spheres (bio-, geo-, atmo-, hydro-) was not new; geomorphologist Bob Sharp opened a 1982 essay on landscape evolution late in his career with the observation that "Planet Earth comprises a succession of nested spheres... [which] constitute a highly differentiated system within which the interface between the solid Earth and the hydrosphere and atmosphere is by far one of the most dynamic. It is at this interface that mankind lives..." It is not surprising then, that workers from the various spheres might see the benefit of working together. What was surprising was how the idea of a "critical zone" was embraced: by students, drawn to the idea of studying the whole entity, by funding agencies, ready to contribute, and by scientists around the world. Perhaps, societies worldwide were finding barriers to problem-solving that were not surmounted by reductionist thinking, particularly for problems that involved overlapping aspects of land, energy, water, climate, social science and other arenas. Perhaps $\mathrm{CZ}$ science was popular because we could not solve knotty problems by working alone.

Hence, critical zone science was born. The science grew rapidly but was also disruptive in that the individual disciplines that comprise $\mathrm{CZ}$ science were no longer running the big funding structures. Eventually, the enterprise was broken back apart into the individual disciplines, starting the cycle again. Perhaps the question is not "whence the CZ?" but rather "whither the CZ?" The evolution of the $\mathrm{CZ}$ science enterprise has shown that we must study the whole ...but we must also somehow trick ourselves to do it in ways that do not detract from the disciplines; that discipline integration produces insight that is greater than the sum of the parts. 